\title{
Advanced control strategy to maximize view and control discomforting glare: a complex adaptive façade
}

Mahdi Valitabar, Ali GhaffarianHoseini, Amirhosein GhaffarianHoseini \& Shady Attia

To cite this article: Mahdi Valitabar, Ali GhaffarianHoseini, Amirhosein GhaffarianHoseini \& Shady Attia (2022): Advanced control strategy to maximize view and control discomforting glare: a complex adaptive façade, Architectural Engineering and Design Management, DOI: 10.1080/17452007.2022.2032576

To link to this article: https://doi.org/10.1080/17452007.2022.2032576

曲 Published online: 04 Feb 2022.

Submit your article to this journal $₫$

View related articles

View Crossmark data $\nearrow$ 


\title{
Advanced control strategy to maximize view and control discomforting glare: a complex adaptive façade
}

\author{
Mahdi Valitabar (D) ${ }^{a}$, Ali GhaffarianHoseini ${ }^{b}$, Amirhosein GhaffarianHoseini ${ }^{\mathrm{b}}$ and \\ Shady Attia ${ }^{\mathrm{C}}$
}

${ }^{a}$ Department of Architecture, University of Zanjan, Zanjan, Iran; ${ }^{b}$ Department of Built Environment Engineering, School of Future Environments, Faculty of Design and Creative Technologies, Auckland University of Technology, Auckland, New Zealand; 'Sustainable Building Design Lab, Dept, UEE, Faculty of Applied Science, University of Liege, Liege, Belgium

\begin{abstract}
Increasing demands for full-glazed façades have motivated designers/ researchers to propose advanced control strategies for dynamic shading systems to mitigate the negative impacts of excessive sunlight penetration into interior spaces. Nevertheless, in line with the latter, outside view is commonly obstructed as a result of utilizing conventional shading systems including Venetian blinds. This is primarily the consequence of conventional systems' lack of flexibility to respond appropriately to occupants' requirements and the sun's changing orientation. This paper presents the virtual prototype development of a Multi-layer blind system through a brute-force algorithm. It emphasizes proposing a customizable and affordable complex shading system with advanced control strategies for multiple building typologies. The research intends to improve visual comfort (daylight and glare) and maximize unblocked window view in a single office room located in Tehran. Furthermore, the control system was developed based on a combination of the cut-off and a glare protection control strategy. Concerning the cut-off control system, the slat angles change to block direct sun radiations, and then, if needed, the position of the front slat, named 'View slat', changes to avoid discomforting glare. In conclusion, the proposed prototype could improve daylight performance by up to $44 \%$ and maximize unobstructed outdoor view by approximately $47 \%$ in an almost glare-free zone. Finally, the usage of swarm intelligence could significantly improve the performance of the proposed prototype by determining which blind and how they should respond to environmental changes and occupants' requirements.
\end{abstract}

Abbreviations: AFs: Adaptive Façades; OF: Openness Factor; OCF: Openness Curvature Factor; MLBS: Multi-layer Blind System; RML: Relative Maximum Luminance; GRV: Glare Response Vote; DA: Daylight Autonomy; Ev: Vertical eye illuminance; sDA: Spatial Daylight Autonomy; WPI: Work-plane Illuminance; DF: Daylight Factor; WFR: Window-to-Floor area Ratio; DGP: Discomfort Glare Probability; DGl: Discomfort Glare Index; UDI: Useful Daylight Illuminance; WPI: Work-plane Illuminance; GSV: Glare Sensation Vote; IV: A numerical score of the interest of a scene, assessed by a group of subjects; DGPs: Daylight Glare Probability simplified; CDA: Continuous Daylight autonomy; PGSV: Predicted Glare Sensation Vote; UDI_a: Useful Daylight Illuminance achieved; GSVs: Glare Sensation Votes
ARTICLE HISTORY

Received 14 July 2021

Accepted 18 January 2022

\section{KEYWORDS}

Dynamic shading system; multi-sectional façade; visual comfort; daylighting;

Venetian blinds; light shelf 
- A brute-force algorithm is used to investigate the visual comfort performance of a multi-layer blind system.

- View and daylight performance of the proposed prototype is significantly improved, compared to commonly used blind systems.

- An efficient and customizable complex AFs is proposed as an alternative to blind systems, applicable to multiple buildings.

- View slats are capable of improving the view quality by enabling occupants to see more view layers compared to commonly used Venetian blinds.

\section{Introduction}

Within the paradigm of automated systems, dynamic building façades, resembling living organisms, have been interpreted as systems whereby reaction of each forming component enables the whole to holistically adapt itself to environmental stimuli (Romano, Aelenei, Aelenei, \& Mazzucchelli, 2018). In comparison with conventional facades, these Adaptive Facades (AFs) are capable of adjusting their real-time behavior in correspondence with environmental variables and dynamic occupants' preferences. Suitable design of AFs presents key challenges, which can be expressed as the combination of (a) satisfying the subjective preferences of diverse users, (b) their objective performance requirements, (c) while responding suitably to varied environmental conditions.

Utilization of dynamic exterior shadings is deemed to provide occupant' comfort and well-being that several experts believe as the most significant performance criteria (Attia, Lioure, \& Declaude, 2020).

AFs are categorized into (1) simple and (2) complex groups based on their motion types. The nonlinear three-dimensional behavior of complex AFs enables them to adapt to multiple façade sections individually, following the occupants' preferences and building energy optimization approaches (Tabadkani, Roetzel, Li, \& Tsangrassoulis, 2021). However, the majority of complex shading systems currently in use or proposed in the literature are defined as a unique answer to a particular design context (Le-Thanh, Le-Duc, Ngo-Minh, Nguyen, \& Nguyen-Xuan, 2021). In this research, the proposed blind system consists of three simple slats widely available in the market. View performance and user positions are also taken into account, making this research a more precise endeavor to propose an optimum alternative for commonly used blind systems.

Blind systems are the most commonly used dynamic shading systems (Konstantoglou \& Tsangrassoulis, 2016). Majority of these though, lack the capacity of changing angles and closing/opening modes simultaneously at each segment of the facade. To this end, this research intends to present an optimum Multi-Layer Blind System (MLBS) with a novel control strategy, with the ability to be generalized for use in multiple buildings. Concerning this theoretical gap, the following research objectives are pursued:

- To investigate the feasibility of proposing customizable complex AFs as an alternative to blind systems.

- To evaluate the impact of integrating an automated MLBS with a dynamic light shelve on view, daylight, and glare.

- To assess the potentials of an innovative blind system in improving both view quality and quantity in an approximately glare-free environment.

\section{Literature review}

Designing/implementing AFs follow certain concerning issues which can be categorized as unaffordability, high operational energy, and design/operation complexity. Mounting complex AFs generally require the usage of additional elements with diverse geometries and varied sizes, which could potentially have adverse effects on window view. On the contrary, simple AFs can be used in multiple 
buildings and are widely available as a cost-effective marketable alternative. Figure 1 illustrates the classification of AFs based on their motion types and proposed prototype with both rotational and translational movements.

As one of the most straightforward daylighting systems, light shelves divide windows into an upper section (clerestory) providing daylight, and a lower part (view). Light shelves can increase the illuminance level at the area close to the window, which can potentially cause discomforting glare and weaken daylight uniformity (Warrier \& Raphael, 2017). However, it has also been reported that; light shelves could improve daylight uniformity hence sacrificing the illuminance level (Ochoa \& Capeluto, 2006). Therefore, internal light shelves are used to decline the illuminance level at the area near the window and direct sun radiations to the deeper apace of the room (Lim \& Ahmad, 2015).

\section{The review approach}

Review of prior artwork in this research followed a systematic literature review approach. ScienceDirect was the domain used to retrieve articles. Literature sources meeting the following criteria and in accordance with a selected range of keywords (as presented in Table 1) were identified for revision.

- Selected papers had to investigate the impact of Venetian blinds on window view as a main research objective.

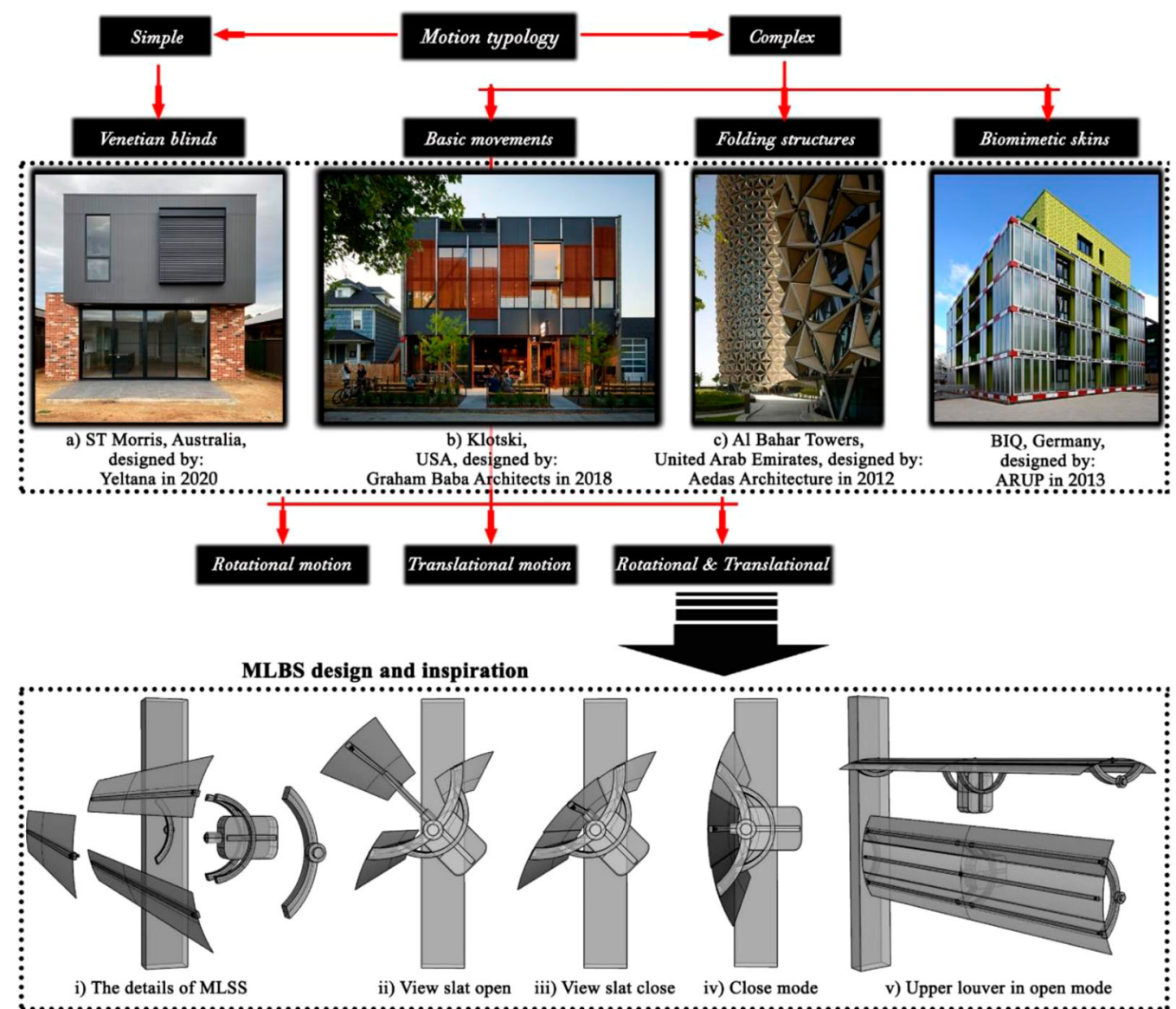

Figure 1. A classification of AFs typologies based on their motion mechanism (Upper row). Different configurations of proposed MLBS (Lower row). 
Table 1. Systematic identification of Venetian blinds and window view literature sources.

\begin{tabular}{|c|c|c|c|}
\hline Database & $\begin{array}{l}\text { Search date } \\
\text { finalization }\end{array}$ & $\begin{array}{l}\text { Inclusion/ exclusion criteria in searching terms in all parts of the document } \\
\text { excluding references }\end{array}$ & $\begin{array}{c}\text { Article } \\
\text { numbers }\end{array}$ \\
\hline ScienceDirect & $16 / 09 / 2021$ & $\begin{array}{l}\text { 'Venetian blind/s' AND ('View out' OR 'View quality' OR 'View outside' OR } \\
\text { 'Outdoor view' OR 'Outside view' OR 'external view' OR 'Window view' OR } \\
\text { 'view clarity') }\end{array}$ & 145 \\
\hline \multicolumn{2}{|c|}{ Time frame2005-2021 } & Subject areasEngineering, Energy, Environmental Science, Material Science & \\
\hline
\end{tabular}

- Papers focusing on a combination of Venetian blinds and other commonly used shading systems were reviewed due to their similarity with the multi-sectional façade being simulated in this study.

- As a limitation of this study, research works exploring advanced glazing technologies were excluded as this is outside of the scope of this research.

- Simulation/modelling is performed based on Venetian blinds with opaque slats. Review of other slat typologies is excluded in this research.

- As an emphasis of this research is to provide occupants with an actual view of the outdoor environment, articles investigating virtual windows were excluded.

This study tries to (a) optimize the number of façade movements while (b) considering window view. Due to the similarity of the proposed system (with a much higher degree of freedom though) with Venetian blinds, review of literature is primarily focused on this typology. Search keywords were clustered into (1) Venetian blinds and (2) Window view. While generally reviewing the identified 145 articles, only 13 research papers which closely matched the criteria were reviewed in depth.

\section{Window view through shading systems}

When designing working environments, with special emphasis on building facades, users need to be put first (Alkhatib, Lemarchand, Norton, \& O'Sullivan, 2020), with especially window view (Lottrup, Stigsdotter, Meilby, \& Claudi, 2015), and natural light (Aries, Veitch, \& Newsham, 2010), playing an important role on their physical and psychological health and well-being. Furthermore, outside view is considered the most crucial factor stimulating occupants to change the blind's openness (Karlsen, Heiselberg, \& Bryn, 2015), and also to switch off shading system controls to provide an outside view or gain more natural light (Meerbeek et al., 2014). A pleasing view is also less likely to attract attention from discomforting glares (Tuaycharoen \& Tregenza, 2007). View comprises of three layers including

(a) Sky, consisting of daylight informing occupants about day, time, season, etc.,

(b) City or Landscape, consisting of environmental information and;

(c) Ground Layer reflecting human activities (Markus, 1967).

View Clarity Index (VCI) is utilized to calculate the view clarity through shadings made of fabric materials (Konstantzos et al., 2015). View clarity correlated to properties of fenestration systems and visual conditions. So that, this metric utilizes visible transmittance and the openness factor of fabric-based products to quantify view. Similarly, Tzempelikos (2008) presented a systematic method to calculate the fraction of projected view of Venetian blinds (Tzempelikos, 2008). This research follows the same approach, using a Rhinoceros Grasshopper algorithm. Nevertheless, this research emphasizes more on the Openness Curvature Factor (OCF) rather than the Openness Factor (OF) since it primarily relies on the user's position and view direction.

\section{Shading control systems}

As the most commonly used strategy, the cut-off angle is an open-loop control system attempting to cut direct sun radiations through changing the blind angle in relation to the sun's position (Chan \& 
Tzempelikos, 2013). Although this control strategy is more commonly used than others (Jain \& Garg, 2018), its functionality in glare protection can be challenged (Wienlod, Frontini, Herkel, \& Mende, 2011). This is primarily since it investigates slats in a flat form however, they are also frequently presented in curved formats too. Besides, the system occasionally ignores the reflections of a sky view or sunlight from the façade of an adjacent building (Motamed, Bueno, Deschamps, Kuhn, \& Scartezzini, 2020).

On the contrary to the cut-off control strategy, glare protection decreases both daylight and outdoor view because the cut-off strategy uses a lower slat angle than the glare protection strategy (Yun, Park, \& Kim, 2017). Providing a glare-free environment, however, was reported as the most important factor in designing working environments (Iwata, Taniguchi, \& Sakuma, 2017). Therefore, in working hours when employees are present, the focus should be on their view and visual comfort (Karlsen, Heiselberg, Bryn, \& Johra, 2016).

\section{Blind systems}

Commonly applied automated blinds consider a tilt angle for the entire façade whereas, multiple tilt angles are required at each segment of the façade concerning varied functions (Olbina \& Hu, 2012). Table 2 reports a summary of relevant studies on Venetian blinds and their effect on the outside view.

Cut-off control is the most favorite control system in Venetian blinds followed by glare protection. Recently, a real-time simulation of lighting was used to control blind systems with an embedded photometric device (Wu, Kämpf, \& Scartezzini, 2019). Similar to a large scale of research in the literature, the real-time simulation control tried to increase view quantity while keeping the glare under a desirable domain. But, what was ignored is the view quality enabling occupants to tolerate a higher glare threshold concerning visible view layers. Analyzing both view quantity and quality in AFs simultaneously, as the main focus of this research, has not been widely covered in the literature so far.

\section{Research methodology}

The research algorithm is developed in Grasshopper, a parametric platform offering various components supporting problem optimizations including:

- Galapagos/ Genetic algorithm

- Octopus/ Hype reduction algorithm

- Colibri/ Brute force algorithm

The most distinctive feature of Colibri compared to Galapagos and Octopus is the ability to reinstate a group of iterations, matching the desired domain of performance criteria using Design Explorer. For instance, the system can show the facade configurations, which could provide the highest amount of unobstructed outside view and natural light for users sitting away from the window when those positioned near the window are not present. Here, the Brute force algorithm as a Multi-objective problem-solving method considers all possible options in view of the number of inputs holistically.

On the contrary, the Octopus (Hype reduction algorithm) tries to reach the optimum trade-offs between research objectives. In fact, a setpoint is suggested for all users. Each user, however, at multiple spots, experiences a different view and daylight performance. Reaching a compromise between all users' preferences is the main objective of this research. User_1 sitting near the window, for instance, has a great view quality and could tolerate a higher illuminance level. This situation enables the system to provide more view and daylight for other users without worrying about discomforting glare for User_1, which could not be achieved by using Octopus. 
Table 2. Summary of key research projects performed on automated blind systems and window view.

\begin{tabular}{|c|c|c|c|c|c|c|c|}
\hline Source & Study type & Visual comfort metrics & View factor & $\begin{array}{l}\text { Shading } \\
\text { reflectance (\%) }\end{array}$ & Shading control & $\begin{array}{l}\text { Building } \\
\text { type }\end{array}$ & Year \\
\hline Wienold (2007) & Simulation & DGP- DGPS & $\begin{array}{l}\text { View } \\
\text { quantity }\end{array}$ & 0.52 & $\begin{array}{l}\text { Manual \& Glare protection } \\
\text { \& Cut-off }\end{array}$ & Office & 2007 \\
\hline Tzempelikos (2008) & Analytical & - & $\begin{array}{l}\text { View } \\
\text { quantity }\end{array}$ & 0.50 & Manual & General & 2008 \\
\hline Karlsen et al. (2016) & Simulation \& Experimental & DA- Ev & $\begin{array}{l}\text { View } \\
\text { quantity }\end{array}$ & - & Multi-objective & Office & 2016 \\
\hline Do and Chan (2020) & Simulation & cDA- DGP- DGPs- Ev- sDA- & $\begin{array}{l}\text { View } \\
\text { quantity }\end{array}$ & 0.70 & Cut-off \& light-redirecting & Office & 2020 \\
\hline Wu et al. (2019) & Experimental & DGP-WPI & $\begin{array}{l}\text { View } \\
\text { quantity }\end{array}$ & - & Model-based & Office & 2019 \\
\hline $\begin{array}{l}\text { Katsifaraki, Bueno, and Kuhn } \\
\text { (2017) }\end{array}$ & Experimental \& Simulation & $\begin{array}{l}\text { DGP- Vertical illuminance- Horizontal } \\
\text { illuminance- DA- DGPs }\end{array}$ & $\begin{array}{l}\text { View } \\
\text { quantity }\end{array}$ & 0.80 & $\begin{array}{l}\text { Cut-off \& Model-based \& } \\
\quad \text { Radiation }\end{array}$ & Office & 2017 \\
\hline Iwata et al. (2017) & Experimental \& Simulation & PGSV & $\begin{array}{l}\text { View } \\
\text { quantity }\end{array}$ & $0.60-0.85$ & Glare protection & Office & 2017 \\
\hline $\begin{array}{l}\text { Pellegrino, Cammarano, and } \\
\text { Savio (2015) }\end{array}$ & Field analysis \& simulation & DF- sDA- UDI_a- ASE-WFR & $\begin{array}{l}\text { View } \\
\text { quantity }\end{array}$ & - & Manual & Educational & 2015 \\
\hline Yahiaoui (2018) & Experimental & DGI & $\begin{array}{l}\text { View } \\
\text { quantity }\end{array}$ & - & Open loop & Office & 2018 \\
\hline Karlsen et al. (2015) & Experimental 40 (subjects) & $\begin{array}{l}\text { DGPs- Vertical illuminance- Horizontal } \\
\text { illuminance }\end{array}$ & $\begin{array}{l}\text { View } \\
\text { quantity }\end{array}$ & - & Cut-off & Office & 2015 \\
\hline Koo, Yeo, and Kim (2010) & Simulation & - & $\begin{array}{l}\text { View } \\
\text { quantity }\end{array}$ & - & Open loop & Office & 2010 \\
\hline Manzan and Clarich (2017) & Simulation & UDI & $\begin{array}{l}\text { View } \\
\text { quantity }\end{array}$ & - & Manual & Office & 2016 \\
\hline Zhang and Barrett (2012) & $\begin{array}{l}\text { Field study \& } \\
\text { Questionnaire survey }\end{array}$ & - & $\begin{array}{l}\text { View } \\
\text { quantity }\end{array}$ & - & Manual & Office & 2012 \\
\hline
\end{tabular}


Finally, Galapagos is incapable of solving multi-objective optimization problems while searching for only the best result.

\section{Research design}

Concerning the attributes of simple and complex AFs, a novel blind system named 'MLBS' with Rectangular-shaped slats was developed. Such slats with defined geometry and materials are widely available worldwide, which could be ordered from a supplier and assembled on a construction site. Designing, construction, and maintenance of this system are cheaper than available complex shading systems. Besides, a three-layer blind system performs better than a single one, especially when it comes to the window view (Valitabar, Moghimi, Mohammadjavad, \& Pilechiha, 2018). Finally, the user is placed in the loop of the shading control system, which was discussed in a small scale of literature (Al-Masrani, Al-Obaidi, Zalin, \& Aida Isma, 2018). Figure 2 shows an overview of the research methodology.

The research is carried out in the following steps:

1. A literature review is done to determine the main attributes of simple and complex AFs.

2. The proposed MLBS consists of three separated slats, which can rotate around a horizontal axis. In addition to tilt angle changes, the middle slat named 'View slat' can move forward or backward, independently, to control glare.

3. Rhinoceros and Grasshopper are used to make the virtual model of the office room. Figure 3 shows the base model, a rectangular-shaped room with $3.6 \mathrm{~m} * 8.2 \mathrm{~m} * 2.8 \mathrm{~m}$ interior dimensions (adapted from (Reinhart, Jakubiec, \& Ibarra, 2013)).

4. Multi-slats in an actual situation could orient independently towards the sun. Furthermore, the view slats can move forward up to $20 \mathrm{~cm}$ from the two back slats. Although this scenario could provide more freedom to the shading system to adapt itself better in response to changes in environmental factors and employees' requirements, it can increase the system's operational energy and become a source of either nuisance or even distraction. Due to technological requirements and time constraints in this research, the simulation factors are limited to 3 groups of the upper, middle, and lower slats, which can have the identical tilt angles. Besides, the view slats of upper and middle slats can be placed in 0,10 , or $20 \mathrm{~cm}$ from the two back slats, while in the lower section, the 0 distance was removed.

5. The research algorithm is designed in Grasshopper using Honeybee plus. Weather data is used to determine the sun's position accurately. The main critical Radiance simulation parameters are expressed in Table 3.

6. Different visual comfort criteria, including DGP, DGI, UDI, and OCF to evaluate outdoor view through multi-layer shadings, were taken into account to investigate the visual performance of the proposed shading system. The main research objectives are $\mathrm{DGP}<35 \%, \mathrm{DGl}<22$, maximize UDI and OCF.

7. In this step, Ladybug Sunlight Hours Analysis is utilized to determine the extreme time hours when occupants at the given positions receive direct sun radiations. During these hours, the value of DGP is in the intolerable range.

8. Colibri plugin for Grasshopper was taken as the optimization procedure to generate 858 models automatically. This plugin was designed to enable users to generate data sets compatible with Design Explorer. This is a 'Brute Force' algorithm in the Grasshopper environment, which assess all possible alternatives to find satisfactory solutions to the optimization problem.

9. Ultimately, a data.csv file generated by Colibri was transferred to Design Explorer to illustrate the results of the visual comfort simulation for 858 façade configurations. 


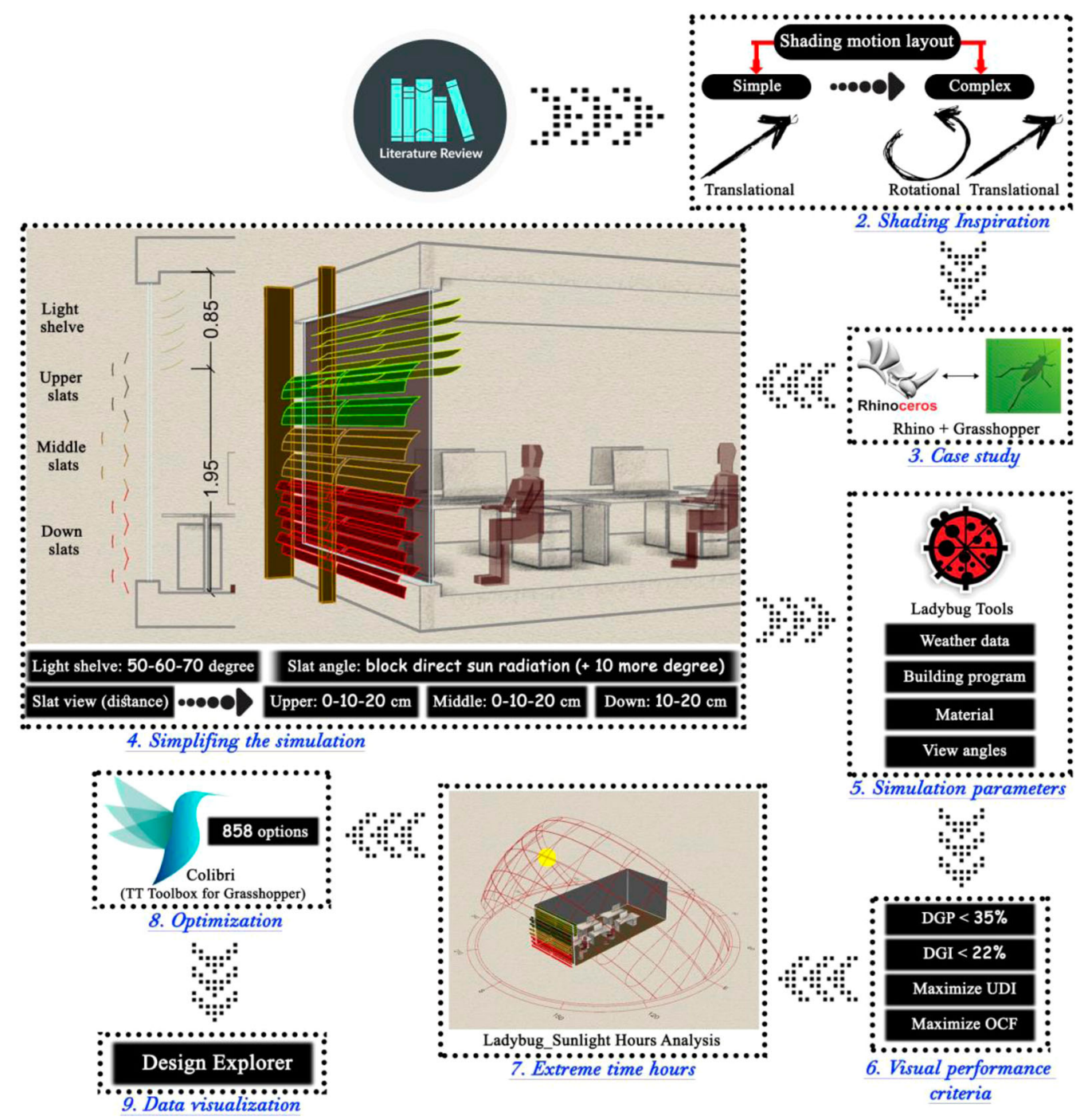

Figure 2. Research design.

Figure 4 represents the research algorithm written in Grasshopper using Honeybee components to calculate the visual comfort metrics.

As Figure 5 illustrates, extreme times/hours were extracted from the Ladybug-Sunlight Hours Analysis component, in which occupants experienced intolerable glare.

\section{Performance metrics}

In this research, various parameters namely DGP, DGI, UDI and OCF, were considered as the main parameters to evaluate the visual comfort performance of the developed blind system.

(EQ1): Discomforting Glare Probability (DGP) was presented by Wienold and Christoffersen (Wienold \& Christoffersen, 2006). In a daylight glare classification presented by Wienold (Wienold, 2009), A level shading system must maintain the DGP value in imperceptible range for $95 \%$ of the occupied time.

(EQ2): Discomforting Glare Index (DGI) was presented to predict glare from major sources, including windows (Carlucci, Causone, De Rosa, \& Pagliano, 2015). 


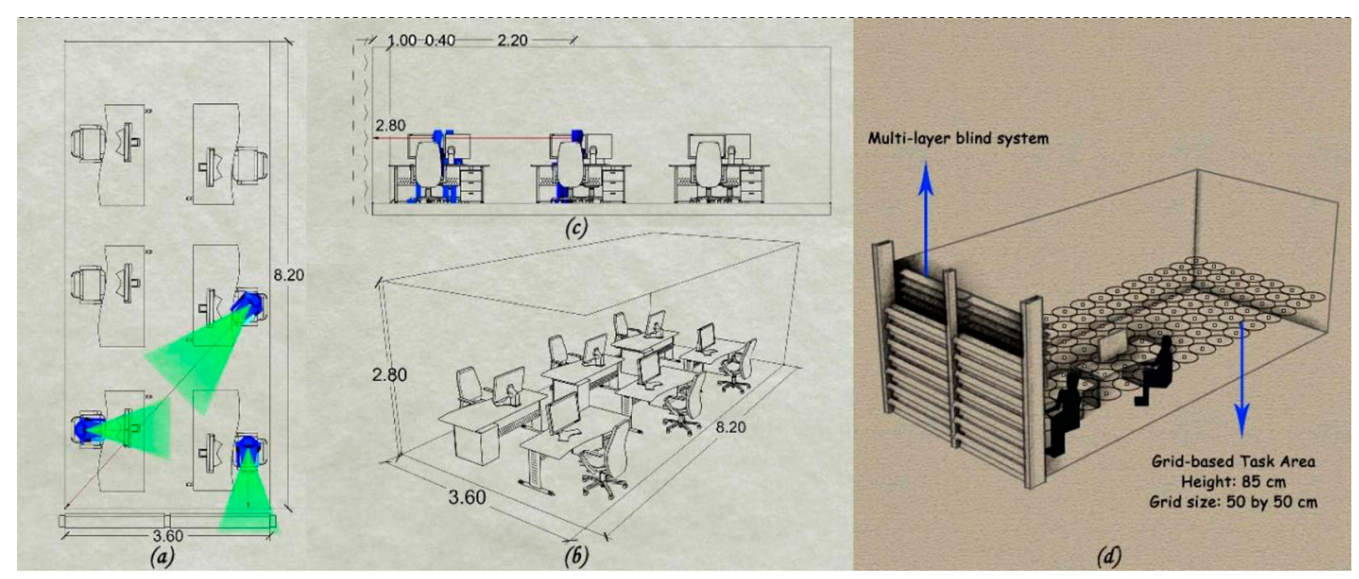

Figure 3. Details of the test model. (a) Plan with user view directions. (b) Isometric perspective. (c) Side view (d) Task area.

Table 3. Radiance setting rendering adapted from (Radiance 2.4., n.d.).

\begin{tabular}{ccccc}
\hline ambient bounce & ambient division & ambient super- samples & ambient resolution & ambient accuracy \\
\hline 3 & 512 & 128 & 32 & 0.25 \\
\hline
\end{tabular}

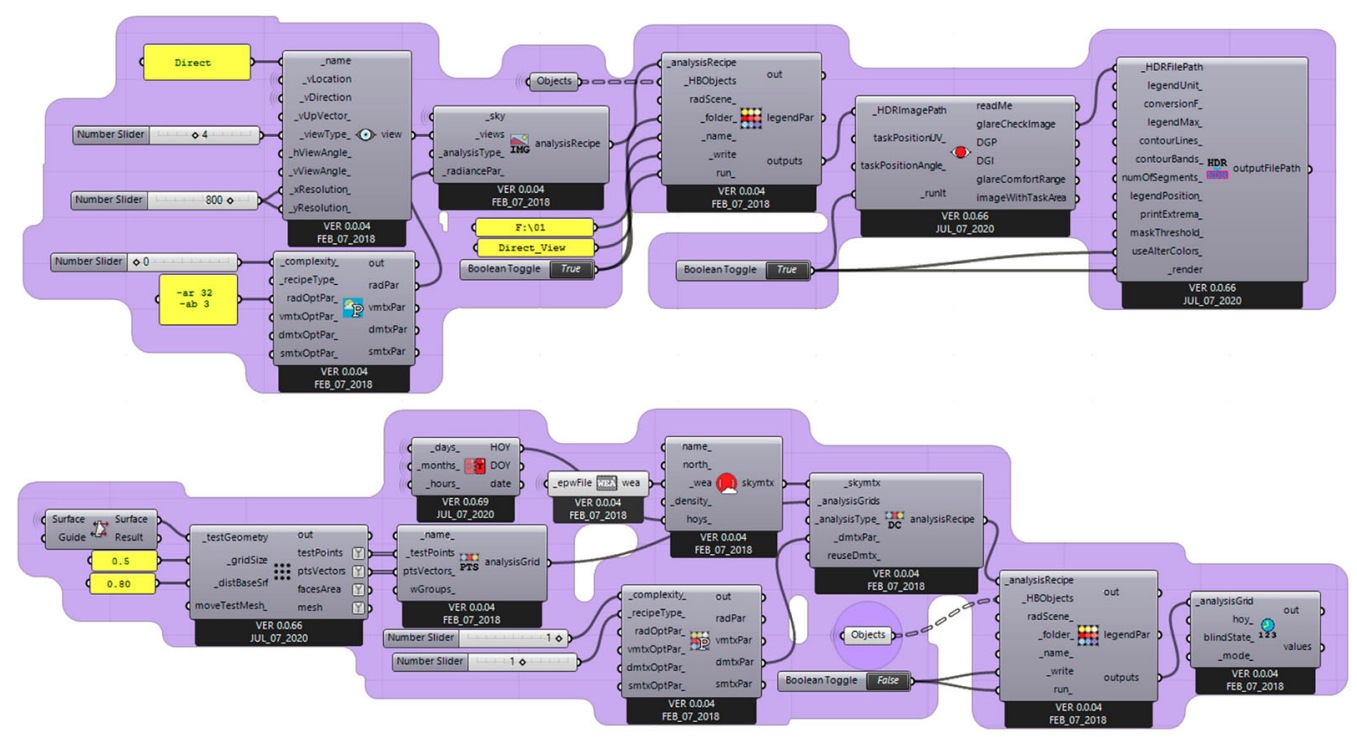

Figure 4. Optimization algorithm written in Grasshopper, upper figure for DGP and DGI, down figure for UDI.

(EQ3): Useful Daylight Illuminance (UDI) is used to simultaneously assess daylight and discomforting glare (Nabil \& Mardaljevic, 2006). It evaluates the percentage of a year when the indoor horizontal daylight illuminance remains in a particular range at a specific test point. It is worth noting that users generally use artificial lighting when the amount of illuminance equals or is under 300 lux (Reinhart \& Voss, 2003). 


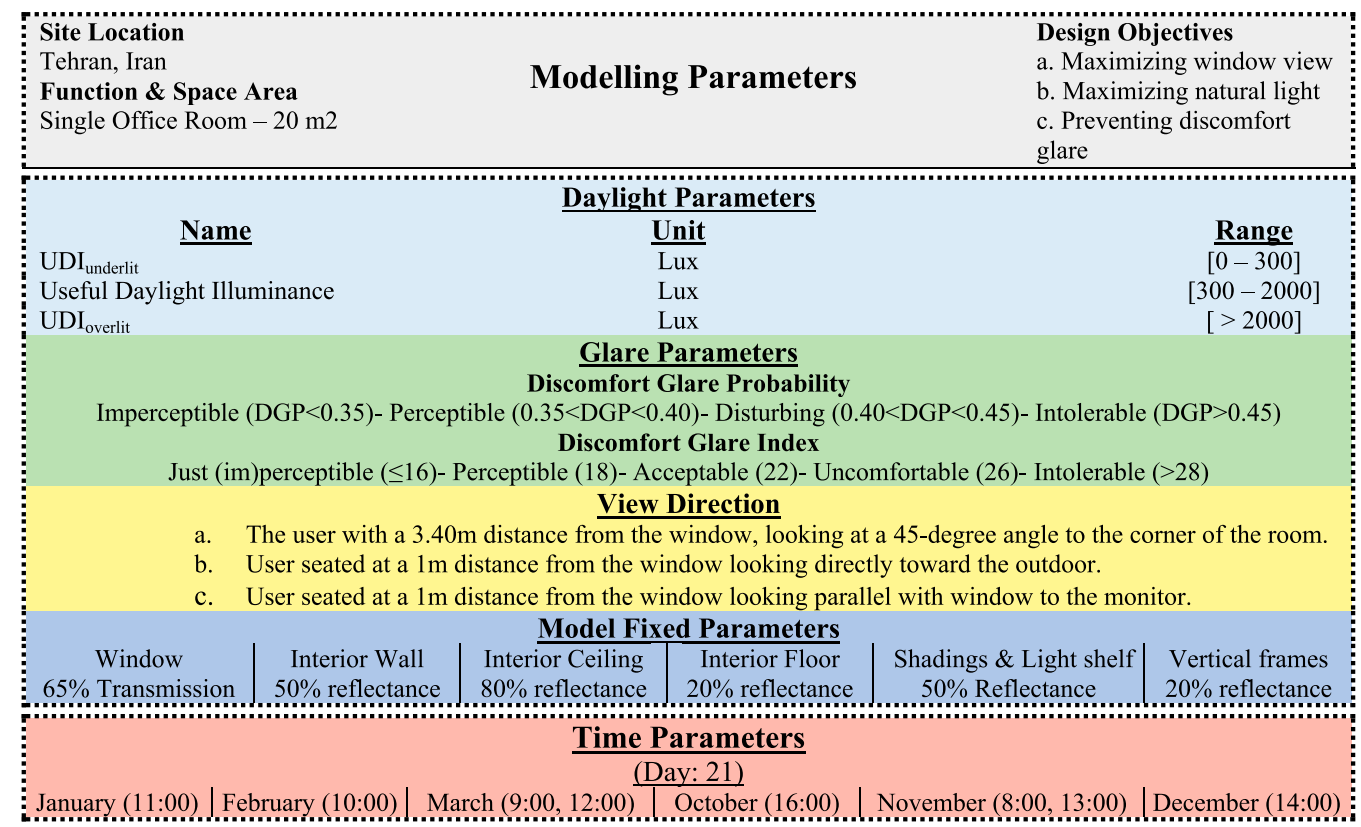

Figure 5. Modeling parameters and performance criteria of simulation.

(EQ4): To evaluate view quantity through the MLBS, as a newly developed metric, Openness Curvature Factor (OCF) was used (Valitabar, Mohammadjavad, Henry, \& Pilechiha, 2021).

$$
\begin{aligned}
& \mathrm{DGP}=5.87 * 10^{-5} E_{V}+9.18 * 10^{-2} \log \left(1+\sum_{i} \frac{L_{s, i}^{2} \omega_{s, i}}{E_{V}^{1.87} P_{i}^{2}}\right)+0.16 \\
& \mathrm{DGI}=10 \log _{10}\left[0.478 \sum_{i=1}^{n}\left(\frac{L_{s, i}^{1.6} * \omega_{s, i}^{0.8}}{L_{b}+0.07 \omega^{0.5} * L_{\text {win }} * P_{i}^{1.6}}\right)\right]
\end{aligned}
$$

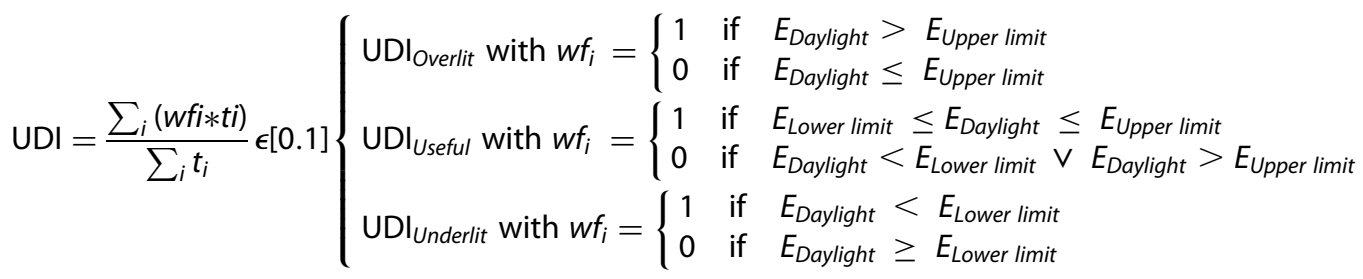

$$
\begin{aligned}
& \text { OCF }=\frac{\frac{\left(\beta_{1}+\beta_{2}\right)}{360} * 2 \pi r}{\frac{\alpha}{360} * 2 \pi r}
\end{aligned}
$$

Figure 6 shows the process and formula of calculating this metric in which instead of a horizontal plane, a vertical one was taken into account to calculate OCF as defined as:

The percentage of unblocked view is based on an arc within the occupant's field of view located on the eyes' horizontal plane. 


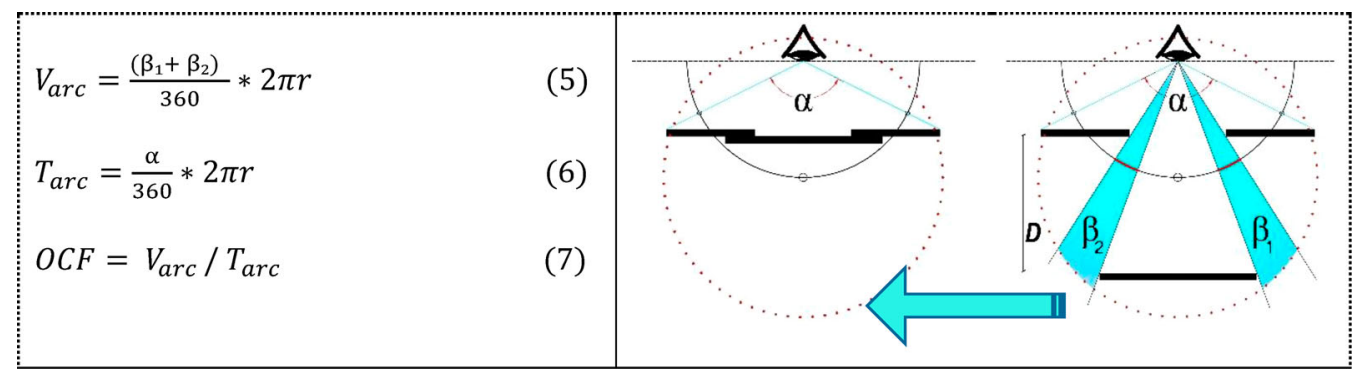

Figure 6. Openness Curvature Factor (OCF)/ adapted from (Valitabar et al., 2021).

\section{Results and discussion}

Concerning performance metrics and simulation settings, results of simulating 858 façade configurations are reported in this section. To better interpret the simulation results, 'Design Explorer' is used to investigate the multi-objective behavior of the proposed prototype. In view to the research objectives to maximize useful daylight illuminance, maintain the DGP value under the imperceptible range, and maximize unblocked outside view, the following numerical values were extracted for each design scenario:

- UDI, UDI (overlit) and UDI(underlit)

- DGP and DGI for two view angles

- OCF for three view directions

- OF

Figure 7 illustrates the simulation results for 858 design layouts in 8 extreme times/hours during which the value of DGP is in the intolerable range in case of an unshaded façade (online link: https:// bit.ly/3kpiM48). As shown in Figure 7, more than 70\% of the task area could receive around 300-2000 lux, whereas the value of undesired UDI (overlit) reached more than $20 \%$. The domain of UDI (underlit), as low illuminance, begins from $10 \%$ to a fully shaded area. Furthermore, a fraction of design options experienced a DGP value of more than 0.30 and a DGl value of more than 20 reflecting the superior visual comfort performance of MLBS. Simulation results indicate a range of $0-60 \%$ OF for all generated models. Admittedly, the higher the OF the higher the direct sun radiations, increasing the risk of discomforting glare.

The outdoor view could not be accurately calculated through exclusively employing OF. An additional metric was required to achieve actual results. Furthermore, there is no meaningful
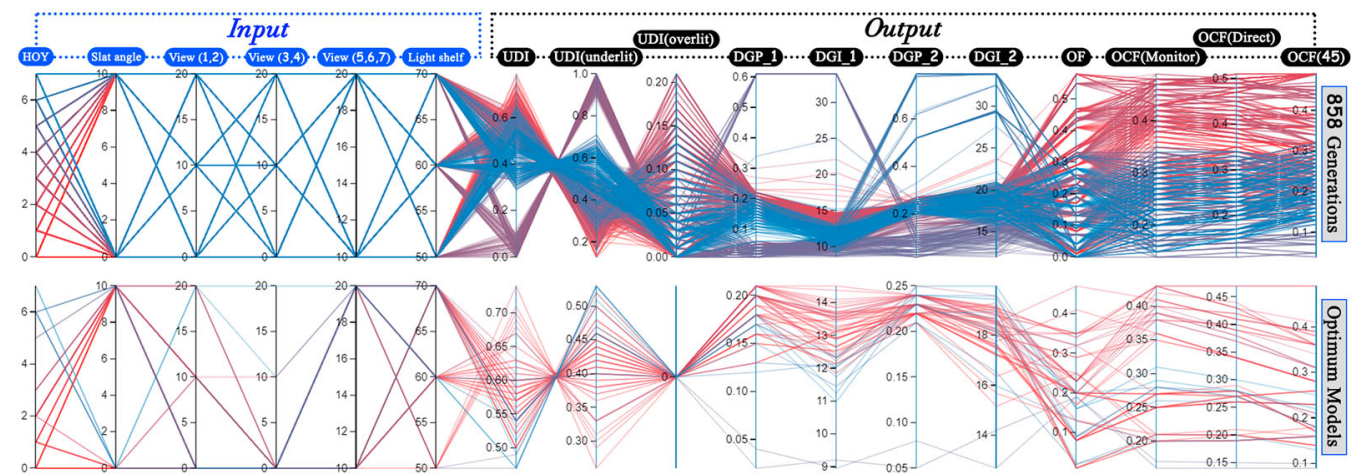

Figure 7. Results of simulation for all 858 scenarios (upper graph), optimum models (lower graph). 
correlation between the user's position and OF while users at each specific point of the workspace can experience different view qualities and quantities. As such, OCF, as a newly developed metric to evaluate outside view at a given user position through a blind system, was also used.

Figure 7 shows a domain of approximately $0-50 \%$ OCF for 3 view directions (Monitor, direct, and 45 degrees).

From the pool of the generated models, a range of optimum alternatives with UDI $>40 \%$, UDI (overlit $=0$ ), DGP $<0.35$ and $\mathrm{DGl}<22$ were considered to investigate the MLBS's performance. Next, alternatives with an undesirable amount of illuminance on the task area (UDI overlit $_{\text {) were }}$ removed. As shown in Figure 7, certain optimum design solutions are presented for each time/ hour except for the 21st of October at 16:00 (online link: https://bit.ly/3tQLIL4). More design configurations of MLBS need to be generated and simulated in order to reach optimum results for this time hour, similar to random model 4 shown in Figure 10. Furthermore, less OCF was observed on 21st November 8:00 (online link: https://bit.ly/3EAwjOm).

In this research, utilization of a commonly used Venetian blind was also simulated and compared with that of the proposed blind system. For this simulation, a rectangular-shaped slat manufactured by (Warema, n.d.) with $150 \mathrm{~mm}$ width, made of a metal-based material with $50 \%$ reflectance (identical with the simulated MLBS) was used. A cut-off strategy was used to control the Venetian blinds, while angles could rotate back up to 20 degrees to have an outdoor view. As shown in Table 4, there is no significant difference between DGP and DGI while the proposed prototype can increase UDI and OCF by up to $22 \%$ and $42 \%$ respectively.

According to Table 4, MLBS could significantly improve OCF on 21st of Feb at 10:00, 21 st of Mar at 9:00, 21st of Mar at noon, and 21st of Nov at 13:00 compared to Venetian blinds. On 21st of Jan at 11:00, the view performance of MLBS and Venetian blinds are similar, however, on 21st of Oct at 16:00, 21st of Nov at 8:00, and 21st of Dec at 14:00, Venetian blinds performed better.

In Section 4.2, manual simulations are run to investigate the performance of the proposed prototype while each slat could move independently.

Figure 8 shows the glare probability of MLBS configurations compared to the Venetian blinds for 4 extreme time hours at different dates. As a key feature of the proposed prototype, multiple sections of the façade could serve different function independently through dividing the slats into right and left sides. For instance, during a cold winter morning, while sunlight could adequately warm up the indoor space, it might cause discomforting glare. In such case, the left side blinds could block direct sun radiations while the right side could be opened to allow adequate daylight and increase outdoor view. Finally, integration of horizontal slats with vertical frames used to hold mechanical components significantly improved the performance of proposed MLBS.

\section{Light shelf and daylight}

Application of light shelves is a promising approach to enhance daylight performance and allow sun radiations into interior spaces without increasing the risk of glare. Figure 9 outlines a comparison of UDI, DGP, and DGI for different scenarios of using shading systems.

- Values of DGP and DGI for all scenarios in the Monitor view are less than the Direct view. Furthermore, it is concluded that; integration of light shelves with either MLBS or Venetian blinds has no major impact on DGP and DGI values in contrast to UDI.

- Appropriate integration of MLBS with light shelves resulted in an approximately glare-free space with over $44 \%$ desirable illuminance.

- UDI value for the MLBS with light shelf is higher than the Venetian blinds in time patterns 1-4.

- UDI value for the MLBS with light shelf was found to be lower than the Venetian blinds in time patterns 5, 6, and 8 . In spite of this, some random design layouts of MLBS, generated and simulated in Section 4.2 (Manual simulation run), could confirm that the proposed prototype can potentially improve both outdoor view and natural light even in time patterns 5,6 , and 8 . 
Table 4. Performance comparison in extreme time hours.

\begin{tabular}{|c|c|c|c|c|c|c|c|c|c|c|}
\hline \multirow{2}{*}{\multicolumn{2}{|c|}{$\begin{array}{l}\text { Extreme time hours } \\
\text { (Day: } 21 \mathrm{st} \text { ) }\end{array}$}} & \multicolumn{6}{|c|}{ Research objectives } & & \multicolumn{2}{|c|}{$\begin{array}{l}\text { Improvement } \\
\text { percentage }\end{array}$} \\
\hline & & \multirow{2}{*}{$\begin{array}{l}\text { DGP1/ DGI1 } \\
0.63 / 24.68\end{array}$} & \multirow{2}{*}{$\begin{array}{l}\text { DGP2/ DGI2 } \\
0.95 / 33.61\end{array}$} & \multirow{2}{*}{$\begin{array}{l}\text { UDI/UDI (overlit) } \\
0.51 / 0.49\end{array}$} & \multirow{2}{*}{$\frac{\text { OCF (Monitor) }}{1}$} & \multirow{2}{*}{$\frac{\text { OCF (Direct) }}{1}$} & \multirow{2}{*}{$\frac{\text { OCF (45) }}{1}$} & & \multirow[t]{2}{*}{ UDI (\%) } & \multirow[t]{2}{*}{ View (\%) } \\
\hline 491 & January & & & & & & & $\begin{array}{l}\text { Shading type } \\
\text { Unshaded }\end{array}$ & & \\
\hline & $11 \mathrm{am}$ & $0.2 / 13.12$ & $0.23 / 16.92$ & $0.56 / 0.0$ & 0.25 & 0.24 & 0.19 & Venetian blinds & & \\
\hline & & $0.18 / 11.85$ & $0.22 / 17.26$ & $0.65 / 0.0$ & 0.25 & 0.26 & $0.23^{*}$ & MLBS (C_286) & 16 & 21 \\
\hline \multirow[t]{3}{*}{1234} & February & $0.75 / 29.34$ & $0.36 / 12.72$ & $0.54 / 0.45$ & 1 & 1 & 1 & Unshaded & & \\
\hline & $10 \mathrm{am}$ & $0.21 / 13.78$ & $0.23 / 16.96$ & $0.58 / 0.0$ & 0.29 & 0.26 & 0.24 & Venetian blinds & & \\
\hline & & $0.2 / 12.42$ & $0.23 / 17.76$ & $0.71 / 0.0$ & 0.36 & $0.34^{*}$ & 0.28 & MLBS (C_145) & 22 & 30 \\
\hline \multirow[t]{3}{*}{1905} & March & $0.78 / 32.13$ & $0.32 / 11.47$ & $0.61 / 0.39$ & 1 & 1 & 1 & Unshaded & & \\
\hline & $9 \mathrm{am}$ & $0.21 / 14.09$ & $0.23 / 17.26$ & $0.61 / 0.0$ & 0.34 & 0.31 & 0.3 & Venetian blinds & & \\
\hline & & $0.21 / 13.63$ & $0.24 / 18.5$ & $0.69 / 0.0$ & 0.41 & $0.41^{*}$ & 0.39 & MLBS (C_170) & 13 & 32 \\
\hline \multirow[t]{3}{*}{1908} & March & $0.56 / 23.72$ & $0.82 / 26.02$ & $0.56 / 0.44$ & 1 & 1 & 1 & Unshaded & & \\
\hline & $12 \mathrm{am}$ & $0.2 / 12.19$ & $0.23 / 16.75$ & $0.62 / 0.0$ & 0.28 & 0.27 & 0.23 & Venetian blinds & & \\
\hline & & $0.2 / 12.13$ & $0.24 / 18.45$ & $0.67 / 0.0$ & 0.39 & $0.38^{*}$ & 0.31 & MLBS (C_297) & 8 & 41 \\
\hline \multirow[t]{3}{*}{7048} & October & $0.2 /-2.14$ & $0.62 / 28 / 71$ & $0.35 / 0.08$ & 1 & 1 & 1 & Unshaded & & \\
\hline & 4 pm & $0.12 / 9.12$ & $0.22 / 16.6$ & $0.16 / 0.0$ & 0.34 & 0.34 & 0.36 & Venetian blinds & & \\
\hline & & $0.06 / 9.33$ & $0.22 / 18.68$ & $0.11 / 0.0$ & 0.34 & 0.31 & 0.31 & MLBS (C_132) & -45 & -16 \\
\hline \multirow[t]{3}{*}{7784} & November & $0.68 / 35.23$ & $0.23 / 8.64$ & $0.61 / 0.37$ & 1 & 1 & 1 & Unshaded & & \\
\hline & $8 \mathrm{am}$ & $0.10 / 11.37$ & $0.19 / 14.17$ & $0.48 / 0.0$ & 0.29 & 0.27 & 0.24 & Venetian blinds & & \\
\hline & & $0.04 / 10.61$ & $0.11 / 15.49$ & $0.44 / 0.06$ & 0.23 & 0.23 & 0.21 & MLBS (C_173) & -9 & -26 \\
\hline \multirow[t]{3}{*}{7789} & November & $0.26 / 3.33$ & $1.0 / 33.74$ & $0.54 / 0.45$ & 1 & 1 & 1 & Unshaded & & \\
\hline & 1 pm & $0.18 / 10.4$ & $0.23 / 16.77$ & $0.51 / 0.0$ & 0.22 & 0.19 & 0.14 & Venetian blinds & & \\
\hline & & $0.18 / 11.74$ & $0.23 / 18.13$ & $0.60 / 0.0$ & 0.28 & $0.27^{*}$ & 0.18 & MLBS (C_435) & 18 & 42 \\
\hline \multirow[t]{3}{*}{8510} & December & $0.24 / 1.62$ & $0.95 / 34.63$ & $0.60 / 0.40$ & 1 & 1 & 1 & Unshaded & & \\
\hline & $2 \mathrm{pm}$ & $0.19 / 10.8$ & $0.24 / 18.25$ & $0.52 / 0.0$ & 0.31 & 0.32 & 0.27 & Venetian blinds & & \\
\hline & & $0.18 / 11.24$ & $0.25 / 19.98$ & $0.47 / 0.0$ & 0.31 & 0.30 & 0.25 & MLBS (C_564) & -11 & -8 \\
\hline
\end{tabular}




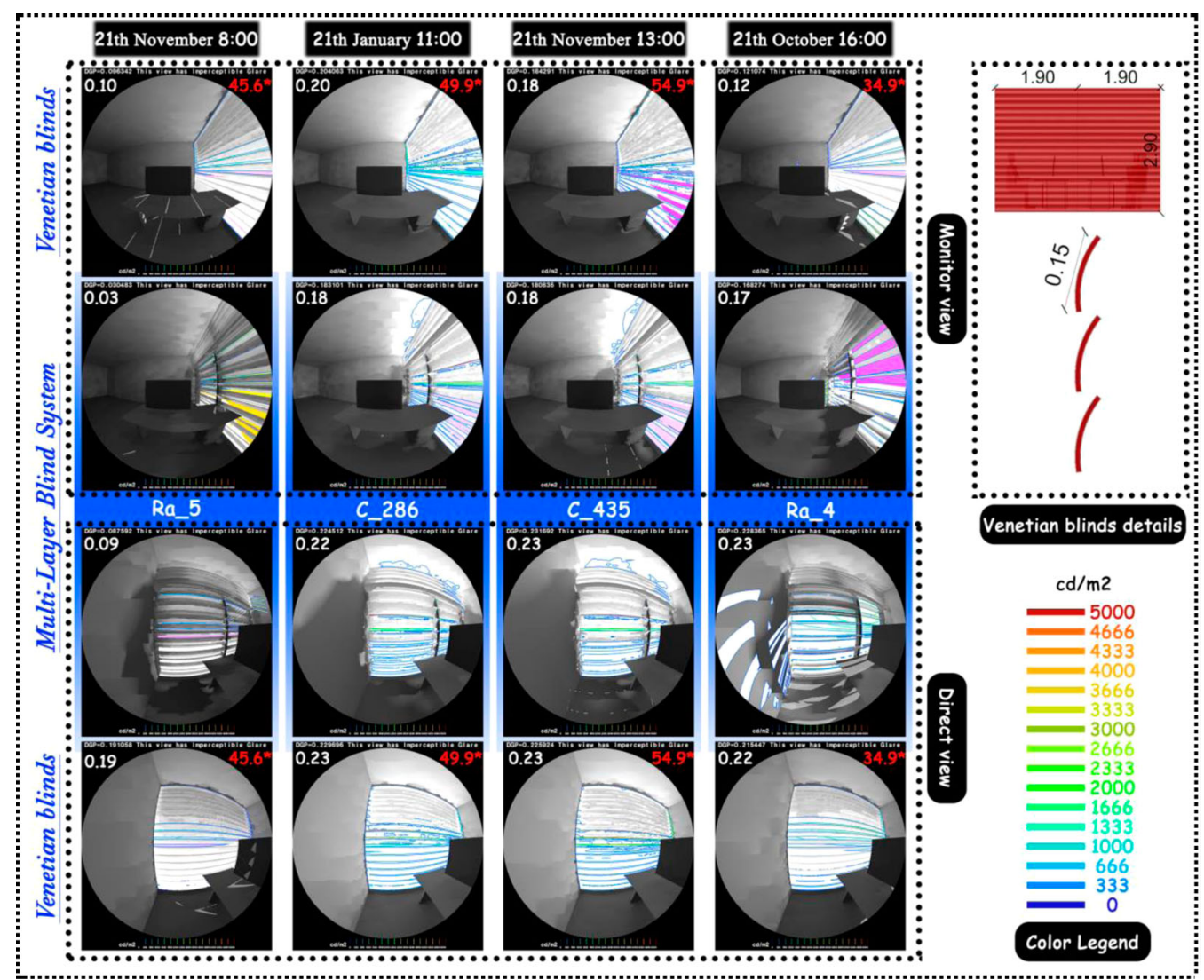

Figure 8. DGP comparison of MLBS and the Venetian blinds (* tilt angle).

\section{Manual simulation run}

Performance of MLBS in a scenario where every single slat is capable of operating independently in response to rapidly changing environmental factors and dynamic user preferences following the highest moving freedom is hereby simulated.

In this case, multiple slat angles are applied to varied façade sections along with different distance values for view slats. A main objective of this research has been to reduce the number of movements. However, identifying the groups of slats required to move simultaneously is concluded to be another necessary parameter to be measured to achieve a comprehensive output. Therefore, in this section, manual simulations are executed to determine whether the performance of MLBS could be improved in 7048,7784 , and $8510 \mathrm{~h}$ of the year. These are the periods during which the results were not satisfactory compared to commonly used blind systems.

Figure 10 illustrates the simulation results for random configurations of MLBS in the above-mentioned extreme time hours. In Figure 7, none of the generated models through automatic simulation process provided a UDI of more than $20 \%$ for 21 st of October at $4 \mathrm{pm}$ This is while configuration number 4 managed to increase UDI and OCF by $44 \%$ and $47 \%$ respectively, compared to standard blind systems. Besides, no significant difference in view performance of model 3 at 2 pm of December 21 st can be observed however, desirable illuminance on the task area was increased by up to $10 \%$.

Considering the sun altitude at 08:00 on the 21st of November, it is impractical to provide an acceptable range of outside view without the risk of glare. Here, conventional blind systems block a considerable fraction of outside view, especially the sky layer. 

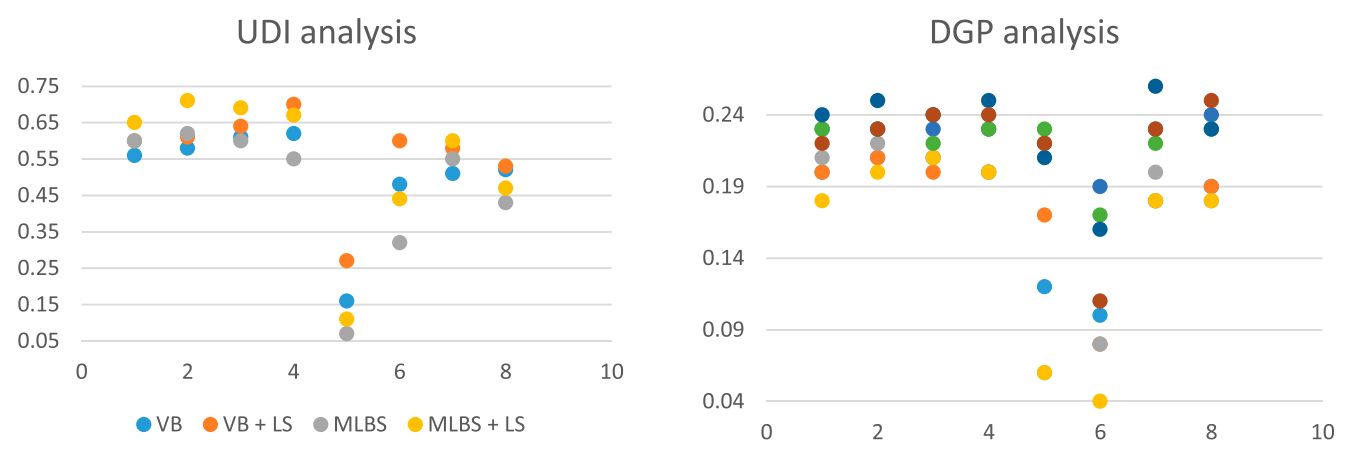

\begin{tabular}{|c|c|c|}
\hline $\begin{array}{l}\text { Horizontal axis } \\
\text { (time pattern): }\end{array}$ & \multicolumn{2}{|c|}{ DGP \& DGI Color Legend: } \\
\hline 1: January 11 a.m. & O & $\begin{array}{l}\text { Venetian blinds (Monitor } \\
\text { view) }\end{array}$ \\
\hline 2: February 10 a.m. & a & $\begin{array}{l}\text { Venetian blinds + light shelf } \\
\text { (Monitor view) }\end{array}$ \\
\hline 3: March 9 a.m. & 0 & MLBS (Monitor view) \\
\hline 4: March 12 a.m. & 0 & $\begin{array}{l}\text { MLBS + light shelf (Monitor } \\
\text { view) }\end{array}$ \\
\hline 5: October 4 p.m. & ? & .Venetian blinds (Direct view) \\
\hline 6: November 8 a.m. & ? & $\begin{array}{l}\text { Venetian blinds }+ \text { light shelf } \\
\text { (Direct view) }\end{array}$ \\
\hline 7: November 1 p.m. & $\mathbf{a}$ & .MLBS (Direct view) \\
\hline 8: December 2 p.m. & - & $\begin{array}{l}\text {.MLBS + light shelf (Direct } \\
\text { view) }\end{array}$ \\
\hline
\end{tabular}

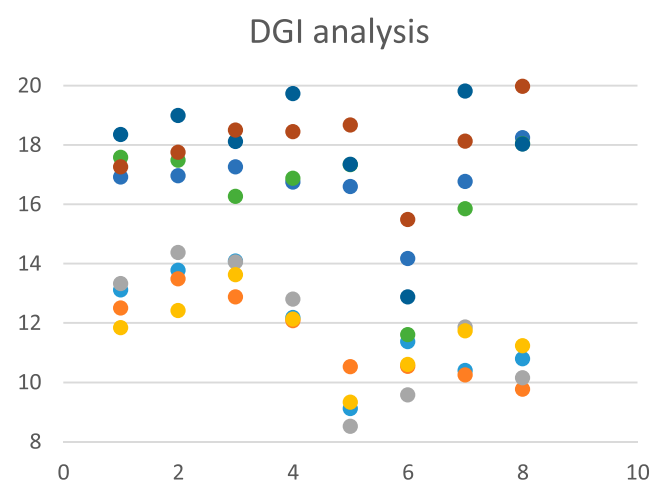

Figure 9. Performance comparison of different shading systems with a light shelf.

As discussed earlier in Figure 7, the least ideal time pattern regarding window view is observed at 08:00 on the 21st of November, in which none of the generated facade configurations provided a OCF of above $25 \%$. Here, two facades ( $1 \& 2$ ) are manually modeled and simulated in this time hour. The results as illustrated in Figure 10, indicating a significant improvement in not only daylighting but also view performance of the proposed prototype. These design solutions improved the UDI by $8 \%$ compared to Venetian blinds, while occupants might experience an undesirable amount of illuminance in some extreme time hours for about $6 \%$ of the task area in case of configuration 2. However, this design layout significantly increased OCF by 65 percent. It also should not be neglected that this configuration of MLBS improves view quality as discussed hereby.

The MLBS (C_2) not only improved the view quantity by $65 \%$ in comparison with Venetian blinds in the least ideal scenario at 8 am on 21 st November, but it also considerably improved view quality, as illustrated in Figure 11.

As a complex system, both rotational and transformational movements enable the MLBS to improve view quality significantly. The most distinctive feature of this proposed system is the view slat, which allows occupants to see all view layers even in extreme time hours. The triple slats block direct solar radiations and simultaneously control glare. Therefore, occupants could see more view layers than conventional Venetian blinds through gaps between view slats and the two back slats, improving the view quality.

Besides, integration of MLBS with light shelves is proven to increase the illuminance level significantly. In case of emphasis being solely on view, with removal of light shelves, utilization of MLBS will further improve view performance allowing occupants a wider access to the unblocked view of the sky layer. 


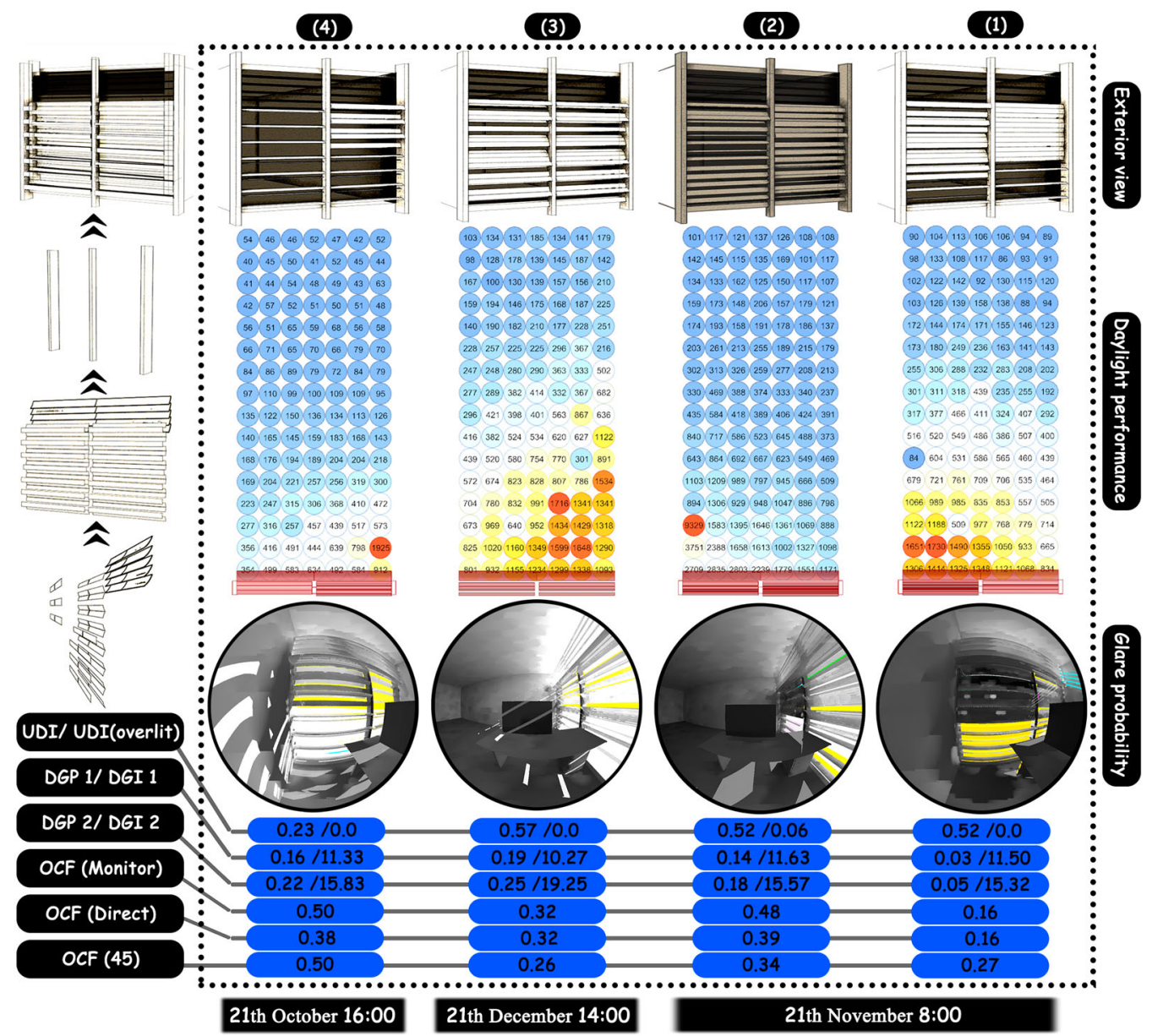

Figure 10. The results of simulation for four façade configurations.

\section{Slats' material and daylight}

MLBS configurations utilized in Table 4 shading type column were modeled in this section to investigate the impact of using different materials during the eight extreme time hours, in which users at the given position felt an intolerable discomforting glare. Figure 12 indicates the material properties and geometry features of slats for both MLBS and light shelves. The light shelf is allowed to tilt within a domain from zero to 34 degrees.

As represented in Figure 13, use of metal slats has a tangible impact on the illuminance level of the task area, while using plastic alternatives could maintain the UDI(overlit) close to 0 . In contrast, the UDI(overlit) value raised dramatically to about $40 \%$ when metal slats were used. As such, combination of using metal slats for the light shelf and plastic slats for the shading system is of the potential to significantly improve the illuminance level, whereas it increases the amount of undesirable illuminance by approximately $5-20 \%$ only in certain extreme time hours.

DGP value of all scenarios is under the imperceptible domain, DGP $<0.35$, except for two design layouts, which are represented in green and red in the DGP graph (Figure 13).

DGP behavior of a system with only plastic slats is perceived to the best among all followed by a system comprised of metal slats for shading and plastic for the light shelf. 


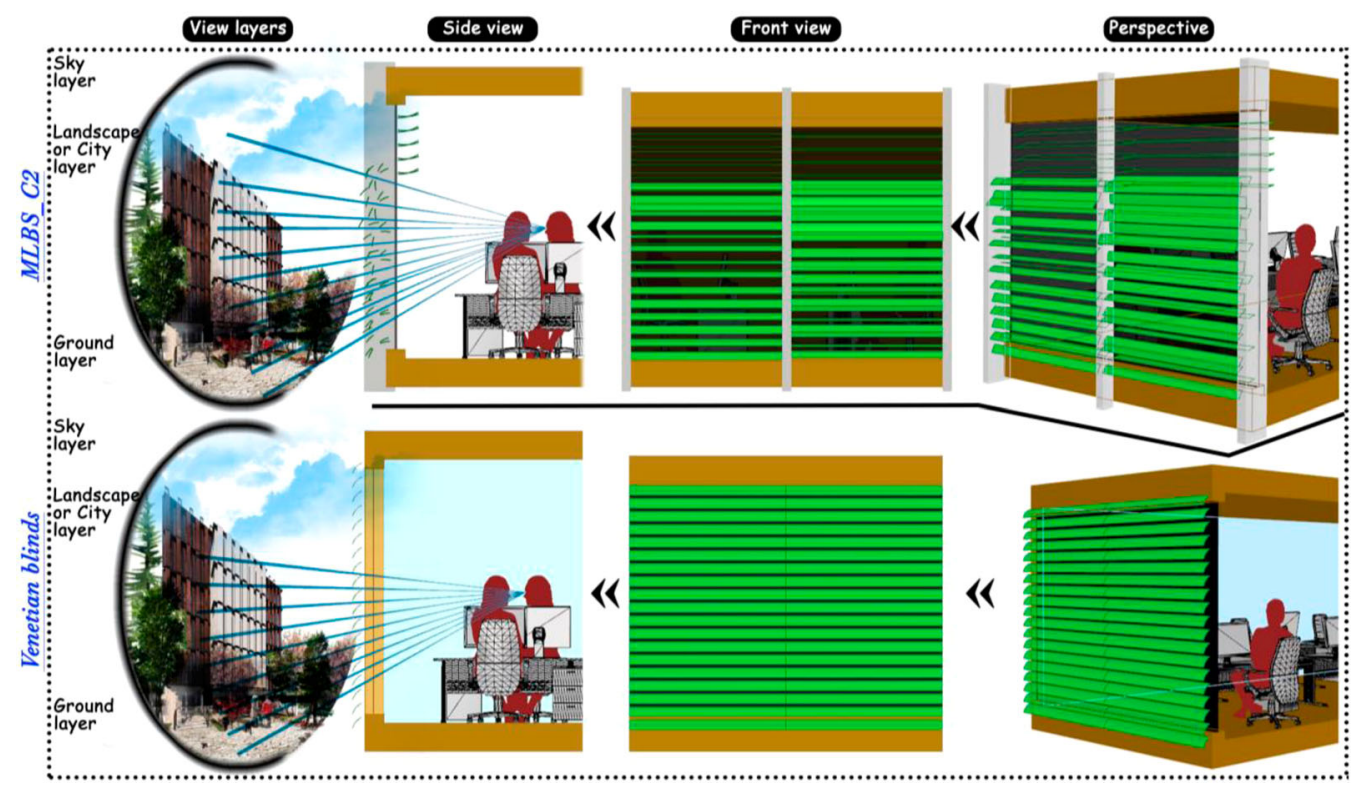

Figure 11. The view quality comparison of MLBS(C_2) with Venetian blind for 21st November 8:00.

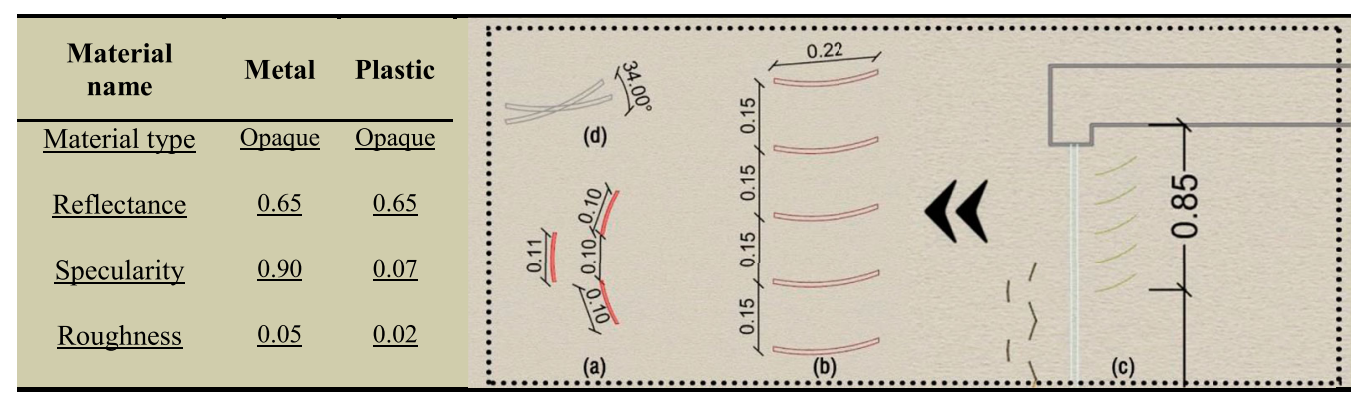

Figure 12. Material properties and geometry features of slats; (a) MLBS. (b) Light shelves dimensions. (c) Light shelves position in the room. (d) Light shelves tilt angle.

But, in contrast to DGP, only three scenarios could meet the research objectives criteria. Indeed, the DGI value for five scenarios went over 22 percent. Again, one of the acceptable scenarios is the one when only plastic slats were used for monitor view. But, the same material for direct view did not meet the research design criteria. In fact, in time pattern 7 the value of DGI for direct view went over 25 percent when using only plastic materials.

In summary, combination of a plastic shading and light shelf system could provide an approximately glare-free environment. Metal slats are not recommended to be utilized for shading systems. Finally, the highest degree of useful daylight illuminance could be achieved via using plastic slats for shading and metal slats for the light shelf system however, daylight uniformity was reduced.

\section{Conclusion}

During this research, effectiveness of implementing an automated blind system (MLBS) was investigated in order to support design of a high-performance Adaptive facade with a high degree of flexibility. The proposed prototype is found to be capable of being utilized in multiple design contexts, 


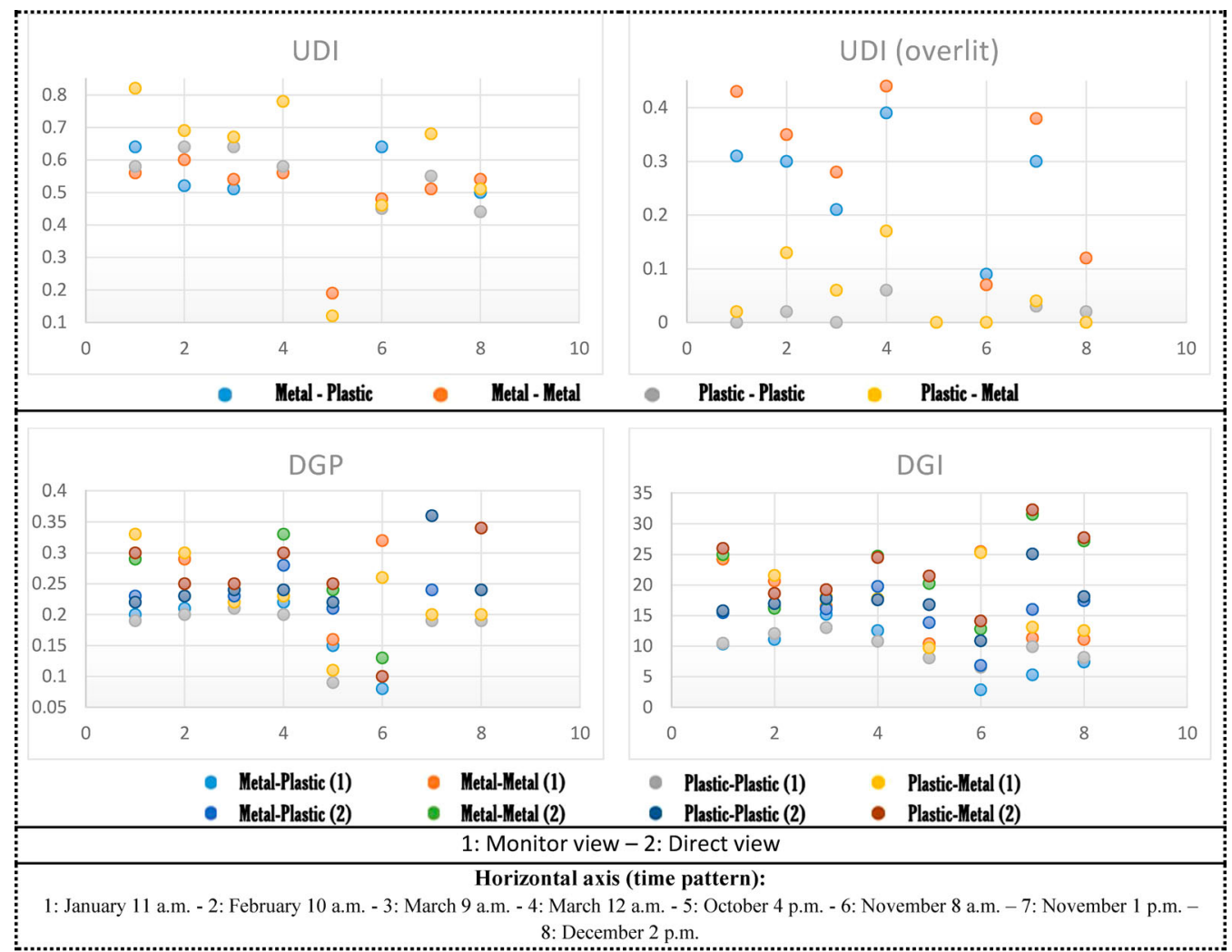

Figure 13. Performance comparison of MLBS with different materials.

hypothetically requiring a lower budget for installation and maintenance compared to currently available complex shading systems. Simulation scenarios implemented in this research considered material settings, geometrical attributes of facade layouts and the vertical frames needed to hold the mechanical details of the proposed complex AFs.

Concerning the outlined research objectives; maximizing unblocked outdoor view, maximizing natural light, and controlling discomfort glare, the proposed method generated 858 design solutions through a brute-force approach to adjust the configuration of the MLBS. This system consists of 7 groups of triple slats, with the middle slats, labeled as View slat which could move forward or backward to control daylight and view, independent from the two other slats.

This research concludes that, MLBS improved daylight performance and outside view by $44 \%$ and $47 \%$ respectively, while DGP and DGI remained under the desirable range. The main research findings of this study are summarized below.

1. This research proposes and confirms the efficiency of customizable complex AFs as an alternative to blind systems, applicable to multiple buildings.

2. Proposed AFs must incorporate independently adjustable tilt angles and view slat positions at multiple sections of the façade to provide optimum natural light, view quantity and quality while controlling glare.

3. Integration of the proposed MLBS with a dynamic light shelf is capable of further improving daylight performance.

4. Separation of slats to left and right sides could significantly improve the performance of the proposed prototype. 
5. Vertical frames used to hold mechanical details of the blind system could improve both view and visual comfort performance.

6. MLBS configurations could be adjusted in response to user positions and preferences, most specifically their window view.

Simulations performed in this research ran for only 8 extreme time hours. Although the proposed method confirms the flexibility of the prototype and its ability to cover varied circumstances at interval times throughout the year, this is still considered a limitation of this research, which can be further investigated on. Experimental research on real-world test cases is required to further corroborate the findings of this research. Eventually, this research anticipates that; swarm intelligence can be employed to precisely determine how slats should respond to changes in environmental conditions and user requirements. This can be further explored in future studies.

\section{Disclosure statement}

No potential conflict of interest was reported by the author(s).

\section{ORCID}

Mahdi Valitabar (D) http://orcid.org/0000-0002-5467-0603

\section{References}

Alkhatib, H., Lemarchand, P., Norton, B., \& O'Sullivan, D. T. J. (2020). Deployment and control of adaptive building facades for energy generation, thermal insulation, ventilation and daylighting: A review. Applied Thermal Engineering, 116331. doi:10.1016/j.applthermaleng.2020.116331

Al-Masrani, S. M., Al-Obaidi, K. M., Zalin, N. A., \& Aida Isma, M. I. (2018). Design optimisation of solar shading systems for tropical office buildings: Challenges and future trends. Solar Energy, 170, 849-872. doi:10.1016/j.solener.2018.04.047

Aries, M. B. C., Veitch, J. A., \& Newsham, G. R. (2010). Windows, view, and office characteristics predict physical and psychological discomfort. Journal of Environmental Psychology, 30(4), 533-541. doi:10.1016/j.jenvp.2009.12.004

Attia, S., Lioure, R., \& Declaude, Q. (2020). Future trends and main concepts of adaptive facade systems. Energy Science and Engineering, 8(9), 3255-3272. doi:10.1002/ese3.725

Carlucci, S., Causone, F., De Rosa, F., \& Pagliano, L. (2015). A review of indices for assessing visual comfort with a view to their use in optimization processes to support building integrated design. Renewable and Sustainable Energy Reviews, 47, 1016-1033. doi:10.1016/j.rser.2015.03.062

Chan, Y. C., \& Tzempelikos, A. (2013). Efficient Venetian blind control strategies considering daylight utilization and glare protection. Solar Energy, 98, 241-254. doi:10.1016/j.solener.2013.10.005

Do, C. T., \& Chan, Y. C. (2020). Evaluation of the effectiveness of a multi-sectional facade with Venetian blinds and roller shades with automated shading control strategies. Solar Energy, 212, 241-257. doi:10.1016/j.solener.2020.11.003

Iwata, T., Taniguchi, T., \& Sakuma, R. (2017). Automated blind control based on glare prevention with dimmable light in open-plan offices. Building and Environment, 113, 232-246. doi:10.1016/j.buildenv.2016.08.034

Jain, S., \& Garg, V. (2018). A review of open loop control strategies for shades, blinds and integrated lighting by use of real-time daylight prediction methods. Building and Environment, 135, 352-364. doi:10.1016/j.buildenv.2018.03.018

Karlsen, L., Heiselberg, P., \& Bryn, I. (2015). Occupant satisfaction with two blind control strategies: Slats closed and slats in cut-off position. Solar Energy, 115, 166-179. doi:10.1016/j.solener.2015.02.031

Karlsen, L., Heiselberg, P., Bryn, I., \& Johra, H. (2016). Solar shading control strategy for office buildings in cold climate. Energy and Buildings, 118, 316-328. doi:10.1016/j.enbuild.2016.03.014

Katsifaraki, A., Bueno, B., \& Kuhn, T. E. (2017). A daylight optimized simulation-based shading controller for Venetian blinds. Building and Environment, 126, 207-220. doi:10.1016/j.buildenv.2017.10.003

Konstantoglou, M., \& Tsangrassoulis, A. (2016). Dynamic operation of daylighting and shading systems: A literature review. Renewable and Sustainable Energy Reviews, 60, 268-283. doi:10.1016/j.rser.2015.12.246

Konstantzos, I., Chan, Y. C., Seibold, J. C., Tzempelikos, A., Proctor, R. W., \& Protzman, J. B. (2015). View clarity index: A new metric to evaluate clarity of view through window shades. Building and Environment, 90, 206-214. doi:10.1016/j. buildenv.2015.04.005

Koo, S. Y., Yeo, M. S., \& Kim, K. W. (2010). Automated blind control to maximize the benefits of daylight in buildings. Building and Environment, 45, 1508-1520. doi:10.1016/j.buildenv.2009.12.014 
Le-Thanh, L., Le-Duc, T., Ngo-Minh, H., Nguyen, Q.-H., \& Nguyen-Xuan, H. (2021). Optimal design of an Origami-inspired kinetic façade by balancing composite motion optimization for improving daylight performance and energy efficiency. Energy, 219, 119557. doi:10.1016/j.energy.2020.119557

Lim, Y. W., \& Ahmad, M. H. (2015). The effects of direct sunlight on light shelf performance under tropical sky. Indoor and Built Environment, 24(6), 788-802. doi:10.1177/1420326X14536066

Lottrup, L., Stigsdotter, U. K., Meilby, H., \& Claudi, A. G. (2015). The workplace window view: A determinant of office workers' work ability and job satisfaction. Landscape Research, 40(1), 57-75. doi:10.1080/01426397.2013.829806

Manzan, M., \& Clarich, A. (2017). FAST energy and daylight optimization of an office with fixed and movable shading devices. Building and Environment, 113, 175-184. doi:10.1016/j.buildenv.2016.09.035

Markus, T. A. (1967). The function of windows - a reappraisal. Building Science, 2(2), 97-121. doi:10.1016/0007-3628 (67) $90012-6$

Meerbeek, B., te Kulve, M., Gritti, T., Aarts, M., van Loenen, E., \& Aarts, E. (2014). Building automation and perceived control: A field study on motorized exterior blinds in Dutch offices. Building and Environment, 79, 66-77. doi:10. 1016/j.buildenv.2014.04.023

Motamed, A., Bueno, B., Deschamps, L., Kuhn, T. E., \& Scartezzini, J.-L. (2020). Self-commissioning glare-based control system for integrated Venetian blind and electric lighting. Building and Environment, 171, 106642. doi:10.1016/j. buildenv.2019.106642

Nabil, A., \& Mardaljevic, J. (2006). Useful daylight illuminances: A replacement for daylight factors. Energy and Buildings, 38(7), 905-913. doi:10.1016/j.enbuild.2006.03.013

Ochoa, C. E., \& Capeluto, I. G. (2006). Evaluating visual comfort and performance of three natural lighting systems for deep office buildings in highly luminous climates. Building and Environment, 41(8), 1128-1135. doi:10.1016/j. buildenv.2005.05.001

Olbina, S., \& Hu, J. (2012). Daylighting and thermal performance of automated split-controlled blinds. Building and Environment, 56, 127-138. doi:10.1016/j.buildenv.2012.03.002

Pellegrino, A., Cammarano, S., \& Savio, V. (2015). Daylighting for Green schools: A resource for indoor quality and energy efficiency in educational environmnets. Proceeding of the International Building Physics Conference, IBPC, 6(78), 31623167. doi:10.1016/j.egypro.2015.11.774

Radiance 2.4. (n.d.). Setting rendering options. Retrieved from https://floyd.lbl.gov/radiance/refer/Notes/rpict_options. html

Reinhart, C. F., Jakubiec, J. A., \& Ibarra, D. (2013). Definition of a reference office for standardized evaluations of dynamic façade and lighting technologies. In Proceedings of BS 2013: 13th Conference of the International Building Performance Simulation Association (pp. 3645-3652).

Reinhart, C. F., \& Voss, K. (2003). Monitoring manual control of electric lighting and blinds. Lighting Research and Technology, 35(3), 243-258. doi:10.1191/1365782803li064oa

Romano, R., Aelenei, L., Aelenei, D., \& Mazzucchelli, E. S. (2018). What is an adaptive façade? Analysis of recent terms and defenitions from an international perspective. Journal of Façade Design and Engineering, 6, 65-76. doi:10.7480/jfde. 2018.3.2478

Tabadkani, A., Roetzel, A., Li, H. X., \& Tsangrassoulis, A. (2021). Design approaches and typologies of adaptive facades: A review. Automation in Construction, 121, 103450. doi:10.1016/j.autcon.2020.103450

Tuaycharoen, N., \& Tregenza, P. R. (2007). View and discomfort glare from windows. Lighting Research and Technology, 39(2), 185-198. doi:10.1177/2F1365782807077193

Tzempelikos, A. (2008). The impact of Venetian blind geometry and tilt angle on view, direct light transmission and interior illuminance. Solar Energy, 82(12), 1172-1191. doi:10.1016/j.solener.2008.05.014

Valitabar, M., Moghimi, M., Mohammadjavad, M., \& Pilechiha, P. (2018). Design optimum responsive façade based on visual comfort and energy performance. Proceeding of the International Conference on Computer-Aided Architectural Design Research in Asia: Learning, Prototyping and Adapting (CAADRIA), 23(2), 93-102.

Valitabar, M., Mohammadjavad, M., Henry, S., \& Pilechiha, P. (2021). A dynamic vertical shading optimisation to improve view, visual comfort and operational energy. Open House International, ahead-of-print. doi:10.1108/OHI-02-20210031

Warema. (n.d.). Internal-venetian-blinds: Slat-geometry. https://www.warema.com/en/internal-venetian-blinds/slatgeometries.php

Warrier, G. A., \& Raphael, B. (2017). Performance evaluation of light shelves. Energy and Buildings, 140, 19-27. doi:10. 1016/j.enbuild.2017.01.068

Wienlod, J., Frontini, F., Herkel, S., \& Mende, S. (2011). Climate based simulation of different shading device systems for comfort and energy demand. Proceedings of the Building Simulation: International Building Performance Simulation Association, 12, 14-16.

Wienold, J. (2007). Dynamic simulation of blind control strategies for visual comfort and energy balance analysis. In Proceeding of the International Building Performance Simulation Association (IBPSA) (pp. 1197-1204).

Wienold, J. (2009). Dynamic daylight glare evaluation. In Proceeding of the International Building Performance Simulation Association (IBPSA) (pp. 944-951). 
Wienold, J., \& Christoffersen, J. (2006). Evaluation methods and development of a new glare prediction model for daylight environments with the use of CCD cameras. Energy and Building, 38(7), 743-757. doi:10.1016/j.enbuild.2006.03. 017

Wu, Y., Kämpf, J. H., \& Scartezzini, J.-L. (2019). Automated 'eye-sight' Venetian blinds based on an embedded photometric device with real-time daylighting computing. Applied Energy, 252, 113317. doi:10.1016/j.apenergy.2019. 113317

Yahiaoui, A. (2018). Experimental study on modelling and control of lighting components in a test-cell building. Solar Energy, 166, 390-408. doi:10.1016/j.solener.2018.03.018

Yun, G., Park, D. Y., \& Kim, K. S. (2017). Appropriate activation threshold of the external blind for visual comfort and lighting energy saving in different climate conditions. Building and Environment, 113, 247-266. doi:10.1016/j.buildenv. 2016.11.021

Zhang, Y., \& Barrett, P. (2012). Factors influencing occupant's blind-control behavior in a naturally ventilated office building. Building and Environment, 54, 137-147. doi:10.1016/j.buildenv.2012.02.016 